Esta revista forma parte del acervo de la Biblioteca Jurídica Virtual del Instituto de Investigaciones Jurídicas de la UNAM

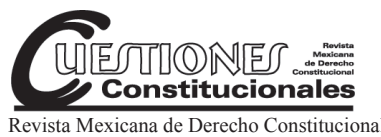

Núm. 37, julio-diciembre 2017

\title{
LA INTERPRETACIÓN INSTITUCIONAL DE LOS DERECHOS FUNDAMENTALES EN UN ESTADO DEMOCRÁTICO DE DERECHO
}

\author{
OFFICIAL INTERPRETATIONS REGARDING FUNDAMENTAL \\ HUMAN RIGHTS IN A DEMOCRATIC STATE
}

\author{
Jaime BASSA MERCADO* \\ Juan Carlos FERRADA BORQUEZ ${ }^{* *}$ \\ Christian VIERA ÁLVAREZ ${ }^{* * *}$
}

RESUMEN: Se ha transformado en un lugar común afirmar que las normas constitucionales con estructura de principio tienen un contenido abierto e indeterminado, el que se concretiza a través de la interpretación constitucional, sin embargo, no existe plena claridad respecto del ámbito competencial que corresponde a los distintos órganos $\mathrm{y}$ actores constitucionales que cumplen dicha función, entre los cuales se anota el legislador, los órganos jurisdiccionales, la administración del Estado y hasta los propios titulares de los derechos fundamentales. Por tal contexto, este trabajo trata de identificar los principales actores en la interpretación de los derechos, proponiendo sus respectivos ámbitos de acción. Postulamos que el ejercicio hermenéutico no es neutro ni avalorativo, sino que supone un importante espacio de discrecionalidad y de creación política de derecho.

Palabras clave: interpretación constitucional, derechos fundamentales, Constitución.
ABSTRACT: It's common to argue that constitutional dispositions with a principle structure have an opened content that requires a concretization through interpretation. However, several institutions assume this function (Legislative, Courts, the administration or the people itself), even if there is no clarity on their specific competence. In this context, the present investigation intents to identify the main responsible of fundamental rights interpretation, proposing their respective competence. We postulate that there is no neutrality in the constitutional interpretation; instead, it is an important amount of discretion and political legal creation. Acy, rule of majority, rights, quality of democracy, amnesty laws, Inter American system of human rights, conventionality control.

Key words: Constitutional interpretation, fundamental rights, Constitution.

* Doctor en Derecho (U. de Barcelona); investigador y académico de jornada completa, Universidad de Valparaíso, Chile.

** Doctor en Derecho, Universidad Carlos III de Madrid, España; Universidad de Valparaíso, Chile.

*** Doctor en Derecho, Universidad de Deusto, España; Universidad de Valparaíso, Chile. 
Esta revista forma parte del acervo de la Biblioteca Jurídica Virtual del Instituto de Investigaciones Jurídicas de la UNAM

\begin{abstract}
SUMARIO: I. Introducción. II. Acerca de la función de la Constitución en la sociedad contemporánea. III. Los intérpretes de las normas constitucionales en una sociedad democrática, en particular de las que contienen derechos fundamentales. IV. Los criterios de interpretación de las normas constitucionales que contienen derechos fundamentales. V. La interpretación y atribución de contenido de las normas de derechos fundamentales:

el caso de la libertad de empresa. VI. Conclusiones.
\end{abstract}

\title{
I. INTRODUCCIÓN
}

Las características de una Constitución política en un Estado contemporáneo se encuentran determinadas, en buena parte, por la configuración actual de las comunidades que legitiman la norma fundamental. Así, en una sociedad democrática de composición plural y diversa que acoge diversas concepciones de la justicia, que protege diversos intereses y pretensiones (económicos y morales), que garantiza, en definitiva, la alternancia en el ejercicio del poder de proyectos políticos incluso contradictorios, la Constitución no es ni puede ser la manifestación de una determinada concepción de la sociedad, ni de un determinado proyecto político, sino un espacio normativo que garantice la más amplia participación y deliberación política. No puede ser concebido de otra forma, toda vez que la fuente de legitimación del ordenamiento constitucional es aquella abstracción sindicada como el pueblo soberano, titular originario del poder constituyente, donde se manifiesta dicha diversidad de intereses y pretensiones.

Por otro lado, independientemente de cómo se redacte una Constitución, su carácter de norma jurídica pone de relieve su condición de fenómeno de manifestación cultural, por lo que tanto el contenido de la norma como su aplicación e interpretación dependen de decisiones políticas, las que se verifican en espacios más o menos deliberativos. En efecto, el contenido material del derecho vigente es contingente, no necesario, de igual modo en que el contenido de los principios y derechos que protege no es autoevidente sino que, por el contrario, resulta de un proceso histórico y dialéctico.

Ese pluralismo y diversidad que caracterizan a la sociedad contemporánea conlleva a la apertura de la Constitución, manifestada a través de la indeterminación de los enunciados normativos de principio (tanto de principios propiamente tal, como de derechos fundamentales), implica una 
Esta revista forma parte del acervo de la Biblioteca Jurídica Virtual del Instituto de Investigaciones Jurídicas de la UNAM

habilitación amplia al legislador para regular ciertas materias relevantes. Eventualmente, su labor de interpretación constitucional será complementada con un proceso deliberativo en sede jurisdiccional, en lo particular cuando éste se verifique mediante un órgano colegiado.

En este contexto, uno de los ámbitos claves en esta apertura del texto constitucional es en materia de derechos fundamentales, configurados como declaraciones normativas que protegen intereses materiales y pretensiones morales, de contenido abierto e indeterminado. Dado dicho carácter, su aplicación y vigencia normativa dependen de cómo la interpretación constitucional concretiza su contenido material, a fin de adjudicar los intereses en controversias jurídicas concretas. Tal concretización es requisito sine qua non para la aplicación de estos enunciados normativos, por cuanto carecen de un contenido sustantivo predeterminado. En efecto, el significado de estos enunciados normativos es atribuido luego de un proceso constructivo a través del cual se les dota de una significación precisa, en lo que Guastini llama una "interpretación decisión". 1

En este marco, sin perjuicio de los desafíos que supone escriturar principios y valores en una norma positiva, es evidente que tras la tarea de concretización del contenido material de las normas constitucionales de principio, se verifica un proceso de expresión y garantía de la libertad política en la configuración del ordenamiento jurídico, a través de la cual se protegen los intereses específicos que están detrás de dichos principios. ${ }^{2}$

En esta perspectiva, el presente artículo analiza cómo debe entenderse la Constitución en un sistema democrático contemporáneo, qué alcances y contenidos tienen sus normas, especialmente aquellas que tienen forma de principio, como las que contienen los derechos fundamentales; quiénes y cómo las interpretan y aplican en una comunidad determinada. Como hipótesis se postula que el ejercicio hermenéutico no es neutro ni avalorativo; por el contrario, supone un importante espacio de discrecionalidad y de creación política en la interpretación de la Constitución, cualquiera sea el órgano o agente que lo realice. Sin embargo, dada la indeterminación de los enunciados normativos que protegen los derechos, su relación con el principio democrático y la garantía institucional de la reserva de ley en su

1 Guastini, Riccardo, Distinguiendo. Estudios de teoría y metateoría del derecho, Barcelona, Gedisa, 1999, pp. 203 y 204.

2 Hesse, Konrad, "Concepto y cualidad de la Constitución", en Hesse, Escritos de derecho constitucional, Madrid, Centro de Estudios Políticos y Constitucionales (CEPC), 2011, pp. 33-56. 
Esta revista forma parte del acervo de la Biblioteca Jurídica Virtual del Instituto de Investigaciones Jurídicas de la UNAM

regulación, sostenemos que dicha interpretación sólo puede ser legítima o suficiente cuando es realizada en sede legislativa.

A estos efectos, este trabajo se estructura en los siguientes apartados: en la primera parte se analizará la función de la Constitución en una sociedad contemporánea; a continuación se revisará quiénes son los intérpretes de las normas constitucionales, en particular las que contienen derechos fundamentales; en tercer lugar se estudiará brevemente los criterios o reglas de interpretación de las normas constitucionales que contengan derechos fundamentales; en cuarto lugar se analizará en un caso concreto el papel que juega la interpretación de una norma constitucional y la subversión de su contenido, utilizando como ejemplo paradigmático la libertad de empresa establecida en el artículo 19, núm. 21 de la Constitución Política de la República; finalmente, se formularán algunas conclusiones.

\section{ACERCA DE LA FUNCIÓN DE LA CONSTITUCIÓN EN LA SOCIEDAD CONTEMPORÁNEA}

\section{La apertura de las normas constitucionales}

1. Se ha asentado en la doctrina actual una clasificación de las normas constitucionales que atiende a su estructura, que distingue reglas de principios; ${ }^{3}$ respecto de las primeras, las reglas, su carácter cerrado admitiría que su interpretación pudiera seguir los criterios tradicionales de interpretación de la ley, recogidos entre nosotros en los artículos 19 al 24 del Código Civil. Sin embargo, esta forma de interpretación de la ley, que persigue una pretendida objetividad característica del paradigma decimonónico de interpretación jurídica ${ }^{4}$ ha suscitado una crisis en la interpretación de la Constitución, en especial cuando estamos ante normas que positivan principios, cuya apertura e indeterminación material impide establecer criterios objetivos y apriorísticos de interpretación.

Sin perjuicio que esta falta de certeza abre un espacio considerable a la discrecionalidad judicial y, por qué no decirlo, también a una eventual

3 Alexy, Robert, Teoría de los derechos fundamentales, sobre "una revisión crítica de la distinción en ALDUNATE”, Madrid, Centro de Estudios Constitucionales, 2010, p. 81.

4 Bassa, Jaime, "La pretensión de objetividad como una estrategia para obligar. La construcción de cierta cultura de hermenéutica constitucional hacia fines del siglo XX", Estudios Constitucionales, 2013, año 11, núm. 2, pp. 25 y ss. 
Esta revista forma parte del acervo de la Biblioteca Jurídica Virtual del Instituto de Investigaciones Jurídicas de la UNAM

arbitrariedad en la interpretación constitucional, ${ }^{5}$ tiene una manifestación positiva de cara al actual contexto de un Estado de derecho constitucional y democrático. En efecto, la apertura estructural de las normas constitucionales puede entenderse como una garantía de libertad política a favor de la comunidad, expresada a través de sus legítimos representantes. ${ }^{6}$ Ésta le permitiría a futuras generaciones concretizar el contenido de estas normas en diversos contextos históricos, sin tener que modificar sustancialmente la Constitución o dictar una nueva, procesos siempre complejos en una sociedad democrática.

Así, dada la diversidad cultural de la sociedad contemporánea, y considerando que la Constitución obtiene de dicha sociedad, la legitimidad que posibilita su efectiva vigencia normativa no se puede establecer como su objetivo el que asuma determinado proyecto particular o que garantice su implementación. Por el contrario, en el actual contexto democrático, la Constitución debiera ser entendida, precisamente, como una garantía para la coexistencia de dicha diversidad. De este modo, dado que no existe a priori una respuesta correcta para las diversas cuestiones que se han incorporado en los textos constitucionales desde la crisis del Estado liberal de derecho, no se puede pretender que la Constitución contenga una definición de este tipo.

Lo anterior es especialmente relevante respecto de las normas de derechos fundamentales, las que dan cuenta de cómo la Constitución contemporánea cumple una función distinta a la que cumplió durante el siglo XIX. Ya no se trata sólo del estatuto que organiza el ejercicio del poder o la declaración formal que garantiza la titularidad sobre derechos de libertad, preferentemente de abstención, sino que el concepto de Constitución ha evolucionado, en especial mediante la incorporación de normas de derechos fundamentales que protegen intereses y necesidades distintas de aquellas que motivaron las revoluciones burguesas. Así, se incorporan, dentro del catálogo de derechos fundamentales, normas que garantizan condiciones materiales de vida, nece-

5 Aldunate Lizana, Eduardo, “Aproximación conceptual y crítica al neoconstitucionalismo", Revista de Derecho, vol. 23, núm. 1, 2010, pp. 79-102. En comparación con Atria, Fernando, "El Tribunal Constitucional y la objeción democrática", Revista Chilena de Derecho, vol. 20, 1998, pp. 367-378, y Atria, Fernando, Los peligros de la Constitución. La idea de igualdad en la jurisdicción constitucional, Santiago, Universidad Diego Portales, 1992.

6 En comparación a Hesse, Konrad, "Concepto y cualidad de la Constitución”, en Hesse, Escritos de derecho constitucional, Madrid, Centro de Estudios Políticos y Constitucionales (CEPC), 2011, pp. 33-56. 
Esta revista forma parte del acervo de la Biblioteca Jurídica Virtual del Instituto de Investigaciones Jurídicas de la UNAM

sarias para el ejercicio de los derechos de libertad formalmente proclamados en las primeras declaraciones. ${ }^{7}$

En ese contexto, la apertura de las normas constitucionales, regulando realidades no contempladas en los textos constitucionales decimonónicos, refleja la diversidad política y cultural en la sociedad contemporánea, lo que se expresa principalmente en el catálogo de derechos fundamentales. En este sentido, tres grandes tradiciones del constitucionalismo se encuentran en el seno del actual catálogo de derechos (liberal, social y democrático), el que recoge una serie de intereses y necesidades reivindicadas por diversos grupos sociales y que el ordenamiento constitucional positiviza en términos universales. Se trata, en definitiva, de la constatación del derecho como un fenómeno cultural y político, donde los procesos que derivan en la constitucionalización de los derechos son empujados desde la propia comunidad que los legitima.

Ahora bien, el modelo de la democracia constitucional y la proclamación de la soberanía popular como fuente de legitimidad del poder supone garantizar también el autogobierno del pueblo que, precisamente, se encuentra limitado por los mínimos positivizados en la Constitución, entre los que destacan las normas de derechos fundamentales. Sin embargo, la legitimidad de estos últimos, de igual forma, es democrática, según nos muestra el proceso histórico de positivización de los derechos a través de sus tres grandes oleadas. Cada uno de estos hitos históricos ha sido empujado por diversos procesos revolucionarios, más o menos violentos, que van desde las revoluciones burguesas de fines del siglo XVIII, hasta la lucha por el fin de los totalitarismos, del colonialismo y de las dictaduras durante el siglo $\mathrm{XX}$.

Dicho antecedente nos muestra que el actual contenido de los catálogos de derechos fundamentales resulta de un proceso complejo, particularmente en los últimos trescientos años; por ello, nos parece que no puede esperarse que ciertos elementos materiales de una Constitución, hoy concebidos como mínimos, sean completamente excluidos del proceso deliberativo. En última instancia, una decisión soberana puede igualmente alterarlos. ${ }^{8}$

7 En comparación a Fioravanti, Maurizio, Los derechos fundamentales. Apuntes de historia de las Constituciones, 4a. ed., Madrid, Trotta, 2003.

8 Sin perjuicio de la función que cumple el derecho internacional de los derechos humanos, tanto como referente cultural en la promoción de los derechos como en la protección normativa a través de los tratados y de sus principios constitutivos, por ejemplo, el de no regresividad de los derechos. 
Esta revista forma parte del acervo de la Biblioteca Jurídica Virtual del Instituto de Investigaciones Jurídicas de la UNAM

Dichos mínimos, o reglas preliminares, también forman parte del proceso político y respecto de ellos se puede revisar su mayor o menor legitimidad.

2. La apertura de la Constitución, en los términos antes descritos, tiene dos grandes manifestaciones. En primer lugar, la presencia de normas constitucionales que, por su estructura, son de contenido abierto e indeterminado, especialmente por su carácter polisémico. Como consecuencia de su estructura, el contenido material de estas normas no puede ser fijado en forma definitiva por el constituyente (como sería el caso, precisamente de las normas de derechos fundamentales), conteniendo lo que la doctrina ha llamado mandatos de optimización. ${ }^{9}$ Se trata, pues, de valores positivizados constitucionalmente que deben ser protegidos atendiendo al contexto histórico, normativo y fáctico de aplicación de la norma en cuestión.

En segundo lugar, la apertura del texto constitucional se manifiesta a través de una serie de materias cuya regulación no es abordada por la Constitución, sino que son dejadas abiertas expresamente por ésta para una concretización posterior, vía legislativa. En efecto, no todas las materias son reguladas con el mismo nivel de detalle por la Carta, tanto porque no es su función regular en detalle cada una de las materias de que trata (escapa a las funciones normativas del poder constituyente originario) como porque dicha regulación de detalle petrificaría no sólo el ordenamiento institucional, sino también las relaciones sociopolíticas que se manifiestan en torno a dichas instituciones. De esta manera, la Constitución deja la reglamentación y concretización de estas normas constitucionales a un acto normativo posterior al momento constituyente, preferentemente de competencia del legislador, mediante la técnica del reenvío directo a éste y de la reserva de ley como garantía de legitimidad de la regulación.

En ambos casos, estamos en presencia del establecimiento de ciertos mínimos que la Constitución contempla para la convivencia democrática de la sociedad, pero cuya concretización no es, ni puede ser, realizada en forma ahistórica en el momento constituyente. Por el contrario, de una forma más o menos consciente, el constituyente originario garantiza el espacio necesario para que sea la propia comunidad, históricamente manifestada a partir de su propio contexto, la que realice (concretice, interprete) ese piso de reglas preliminares que se han positivizado en la Constitución. Esta garantía de libertad política se manifiesta, principalmente, a través de las potestades normativas del

9 Alexy, Robert, Teoría de los derechos fundamentales, Madrid, Centro de Estudios Constitucionales, 2002, pp. 81-87. 
Esta revista forma parte del acervo de la Biblioteca Jurídica Virtual del Instituto de Investigaciones Jurídicas de la UNAM

legislador, como principal órgano de representación política de las sensibilidades que conviven en la sociedad, tanto de la mayoría como de las minorías, expresando así el sentido democrático de la reserva de ley.

En efecto, en el contexto de una sociedad democrática es normal que una serie de materias no queden cerradas y bloqueadas por la Constitución a una regulación posterior, por cuanto se trata de aspectos sensibles de la organización política. La sensibilidad de estos elementos deriva de una combinación entre su importancia para la convivencia democrática y el razonable desacuerdo que existe en torno a ellas, razón por la cual no se identifican con las reglas preliminares de la Constitución. Entre ellas, siguiendo a Hesse, se encuentra el tipo de organización económica que se dará la sociedad, la participación del Estado en la actividad económica o la carga impositiva que deberán soportar los ciudadanos, por nombrar algunas, materias en las que es posible encontrar discrepancias razonables en una sociedad determinada.

Así, la Constitución contemporánea se entiende como una estructura de normas que garantizan mínimos, y no como la materialización de un determinado proyecto político de sociedad. Por eso, se afirma que la Constitución debiera ser concebida como la positivización de ciertos mínimos éticos, reglas preliminares del juego democrático destinadas a garantizar su plena realización, y no como un techo de máximos éticos que restrinja las posibilidades de concretización y de realización de la sociedad, lo que se expresa en la formulación de una Constitución de "techo ideológico abierto". ${ }^{10}$

De este modo, así como los derechos fundamentales, que emanaron de las revoluciones burguesas se identificaron con los intereses económicos y culturales de un determinado grupo social dominante en ese momento, que luego fueron reconocidos como derechos de titularidad universal, posteriormente ocurrirá algo similar con las reivindicaciones sociales y las de carácter democratizador en los siglos XIX y XX; este proceso derivará en la constitucionalización de los derechos sociales, el fin de las dictaduras y totalitarismos, y en la calificación de discriminatorias de una serie de categorías antes consideradas razonables, como las relacionadas con la raza, el sexo o la religión, entre otras.

Este proceso histórico muestra la progresiva positivación y ampliación de los derechos fundamentales, lo que responde al reconocimiento y pro-

10 Zúñiga Urbina, Francisco, "Reformas constitucionales para un Estado social y democrático de derecho”, Colección Ideas, núm. 33, 2003, pp. 27 y 28. 
Esta revista forma parte del acervo de la Biblioteca Jurídica Virtual del Instituto de Investigaciones Jurídicas de la UNAM

tección de las diversas necesidades de las personas en la sociedad, quienes se asocian a la realización de su dignidad, fin último de una sociedad democrática. El resultado de este proceso deriva en un catálogo de derechos cuyo contenido es, ciertamente, contingente, pero que nos muestra la igual valoración de los intereses que representan las tres tradiciones del constitucionalismo contemporáneo.

En este contexto, no podemos afirmar que las reivindicaciones liberales son más importantes que las de género, por ejemplo, o que las raciales más que las sociales. Tras todas ellas existen determinados intereses y necesidades que la comunidad asocia a la protección de la dignidad de las personas que, en principio, son todas iguales en la titularidad y en el ejercicio de los derechos que se positivan como consecuencia de este proceso. Sólo así se puede entender el tránsito desde el sistema de privilegios del Antiguo Régimen al sistema de derechos del Estado de derecho.

Desde esta perspectiva, la única forma en que una Constitución puede garantizar y proteger adecuadamente los intereses que provienen de estas tradiciones, es estableciendo las reglas mínimas para su convivencia, mas sin comprometerse con los intereses de ninguna de aquéllas. La neutralidad ideológica que se predica del Estado debe predicarse también de la Constitución, pero no en términos de negar la existencia de un proyecto político en ésta, pues el propio constitucionalismo lo es, sino en cuanto no debe asumir como propio uno de los proyectos en disputa en el seno de la sociedad, particularmente en un contexto cultural y normativo que se construye desde la constitucionalización del principio democrático.

\section{El contenido y sentido del pacto del poder constituyente originario} en una sociedad democrática

En consecuencia, es posible afirmar que no es la Constitución la que manda a una comunidad, sino que es ésta quien formula las preguntas adecuadas para la solución de los conflictos sociales. ${ }^{11}$ En ello consiste la pretensión de vigencia temporal indefinida que presenta toda Constitución, la cual se explica por la función que una Constitución está llamada a cumplir en una sociedad democrática, que no es preservar las pretensiones políticas del grupo social o económico que, accidentalmente, ha dado una redacción

11 Zagrebelsky, Gustavo, op. cit., pp. 87 y 88. 
Esta revista forma parte del acervo de la Biblioteca Jurídica Virtual del Instituto de Investigaciones Jurídicas de la UNAM

determinada al texto constitucional. Muy por el contrario, la Constitución contemporánea, tributaria de esta triple tradición constitucional, garantiza que las reglas del juego democrático posibiliten la libre manifestación de las cambiantes pretensiones políticas futuras y su alternancia en el ejercicio del poder.

En efecto, si asumimos que el poder constituyente originario radica en el pueblo y no se identifica con el órgano que, accidentalmente, redacta una Constitución, ${ }^{12}$ es necesario concluir que la fuente de legitimidad es, precisamente, política y no orgánica o funcional. Así, una determinada manifestación de la voluntad del pueblo, condicionada por un momento histórico en particular, en principio no tiene legitimidad suficiente para imponerse a las futuras manifestaciones democráticas de ese mismo pueblo, el que puede presentar precisamente un consenso político de diferente contenido.

Como consecuencia de lo anterior, el poder constituyente derivado puede tener, incluso, un mayor peso específico que el originario en la función de interpretar y aplicar la Constitución. El contenido normativo de la decisión constituyente originaria no es inmutable, porque la dimensión política y fáctica de la expresión soberana impide que ello así sea. La fuente de legitimidad de la decisión constituyente radica en una comunidad esencialmente cambiante, que busca en la Constitución soluciones a los diferentes conflictos que se presentan en su seno. Esas soluciones, particularmente las que dicen que tienen relación con la protección y la garantía de los derechos fundamentales, se construyen a partir de las interpretaciones posibles del texto constitucional vigente. Por lo tanto, dado el carácter abierto e indeterminado de las normas de derechos fundamentales, no existe tras ellas un único significado posible, sino que una diversidad de significados cuya concretización dependerá de cómo se argumenta determinada decisión.

Así, la concretización de la norma constitucional no depende de la decisión política manifestada en el momento constituyente, sino de una serie de decisiones normativas posteriores que materializan los contenidos posibles de la norma fundamental. Prueba de ello son las leyes de reforma e interpretativas de la Constitución, las leyes que desarrollan o complementan preceptos constitucionales (principalmente en el caso de las materias de

12 Bassa Mercado, Jaime, "Notas para una teoría democrática del poder constituyente”, Nomos, núm. 1, 2008, pp. 41-70. En comparación a Böckenförde, Ernest-Wolfgang, "El poder constituyente del pueblo. Un concepto límite del derecho constitucional", Estudios sobre el Estado de derecho y la democracia, Madrid, Trotta, 2000, pp. 159-180. 
Esta revista forma parte del acervo de la Biblioteca Jurídica Virtual del Instituto de Investigaciones Jurídicas de la UNAM

reserva de ley o de reenvío del legislador), o las sentencias que emanan de los órganos que conforman la justicia constitucional (las cortes en la protección de los derechos fundamentales y el Tribunal Constitucional en la protección de la integridad del ordenamiento jurídico). Ello deriva en una creciente relativización del momento constituyente originario como factor suficiente y/o legítimo de interpretación constitucional auténtica; en el caso de la Constitución chilena vigente se ve incrementado por las objeciones jurídicas y políticas que se formulan al trabajo desarrollado durante la década de 1970 por la Comisión de Estudios de la Nueva Constitución, el Consejo de Estado y la Junta de Gobierno. ${ }^{13}$

Por lo demás existe una tensión generacional evidente entre ambos momentos históricos, el que determina la generación de la norma y el correspondiente a su aplicación, donde: "La generación presente se siente responsable del destino de las generaciones futuras, mientras que el modelo que pudieron representar las generaciones pasadas pierde su carácter vinculante". ${ }^{14}$ Esa decisión política, que se manifiesta históricamente, tiene una pretensión de permanencia que se hace explícita en los quórum reforzados para su revisión; pero al mismo tiempo se rebela contra las decisiones pasadas, que restringen e incluso condicionan el contenido de sus decisiones.

Estas decisiones políticas, que se relativizan tanto histórica como culturalmente entre sí, se manifiestan a través de sendas normas jurídicas de diverso contenido material. Dado que estas decisiones políticas que se manifiestan normativamente responden a condicionamientos políticos y culturales históricamente determinados, no es posible establecer una preferencia entre ellas. Esta tensión generacional no se resuelve, a priori, a favor de ninguna de las partes, ya que no es función de la Constitución ni de la democracia constitucional actualmente vigente petrificar el contenido de

13 Hay una serie de objeciones que es posible formular al trabajo de la Comisión Ortúzar, que la deslegitiman como fuente suficiente e incluso, necesaria de interpretación constitucional. Puede consultarse, entre otros, Aldunate Lizana, Eduardo, Derechos fundamentales, Santiago, Legal Publishing 2008, pp. 301 y 302; Bassa Mercado, Jaime, El Estado constitucional de derecho. Efectos sobre la Constitución vigente y los derechos sociales, Santiago, Legal Publishing, 2009, pp. 36-43; Celis Danzinger, Gabriel, "Los derechos económicos, sociales y culturales en la interpretación constitucional chilena", Revista del Doctorado y Magíster en Derecho, 2007, núm. 1, pp. 43-74; Waldron, Jeremy, Derecho y desacuerdos, Madrid, Marcial Pons, 2005, pp. 29-60.

14 Habermas, Jürgen, "La soberanía popular como procedimiento", en Jürgen, Habermas, Facticidad y validez. Sobre el derecho y el Estado democrático de derecho en términos de teoría del discurso, Madrid, Trotta, 1998, p. 594. 
Esta revista forma parte del acervo de la Biblioteca Jurídica Virtual del Instituto de Investigaciones Jurídicas de la UNAM

estas normas y, de paso, garantizar la permanencia del proyecto político en particular que ha sido positivado en ellas. Por el contrario, tanto la apertura de las normas constitucionales de principio como el propio procedimiento democrático garantizan la libertad política de la comunidad en la configuración de su propio ordenamiento normativo. De este modo, salvo elementos muy básicos de la convivencia democrática (las reglas preliminares de la democracia) ${ }^{15}$ no debieran existir decisiones vedadas a la deliberación democrática del soberano.

En este contexto, la Constitución se erige como una garantía de dicha deliberación, estableciendo límites pero sin condicionar su resultado. Una lectura de la fórmula "democracia constitucional", que permita la adecuada realización de ambos componentes debe asumir que junto con limitarse, éstos se garantizan recíprocamente; es decir, la valoración de la decisión tomada en el momento constituyente no puede llevarse al extremo de vaciar de contenido a la garantía democrática del autogobierno. Así como existe un límite que la democracia reconoce en la necesidad de proteger las reglas preliminares que garantizan su propia existencia, la Constitución ve limitada su pretensión de inmutabilidad por la libertad política del soberano. Ambos factores se garantizan entre sí, a la vez que se relativizan.

Ahora bien, dado que el contenido del pacto político del momento constituyente es relativo y puede, eventualmente, ceder ante la libertad política del soberano, cobra gran relevancia la forma a través de la cual se concretiza el contenido de dicho pacto, específicamente el contenido de las normas que lo positivan, para permitir su aplicación y ejecución. En este sentido, es muy relevante en una sociedad democrática la forma cómo se concreta la interpretación constitucional, actividad que realizan diversos actores del contexto institucional, y no sólo los jueces, como algunas veces se sostiene.

\section{LOS INTÉRPRETES DE LAS NORMAS CONSTITUCIONALES EN UNA SOCIEDAD DEMOCRÁTICA, EN PARTICULAR DE LAS QUE CONTIENEN DERECHOS FUNDAMENTALES}

1. Ante la necesidad de interpretar las normas constitucionales de contenido abierto e indeterminado, la combinación de los elementos señalados nos lleva a preguntarnos ¿dónde radica la legitimidad para interpretar la Constitución?

15 Bobbio, Norberto, Teoría general de la política, Madrid, Trotta, 2003, pp. 256-259. 
Esta revista forma parte del acervo de la Biblioteca Jurídica Virtual del Instituto de Investigaciones Jurídicas de la UNAM

Es decir, ¿quién se encuentra legitimado para interpretar la Carta? En efecto, el poder constituyente no determina el contenido material de las normas constitucionales abiertas ni puede hacerlo sin vulnerar la libertad política que garantiza la propia Constitución. Deja esta función a los poderes constituidos.

En el caso del ordenamiento jurídico chileno, éste contempla diversos órganos competentes para la interpretación de las normas constitucionales, como son: los órganos colegisladores (presidente de la República y Congreso Nacional), los tribunales ordinarios de justicia (especialmente, las cortes de apelaciones y la Corte Suprema) y, desde luego, el Tribunal Constitucional. Cada uno de estos órganos, en el contexto de las funciones que ejercen en el entramado institucional vigente, participan activamente, con mayor o menor conciencia, de la interpretación de la Constitución y, en consecuencia, de la concretización y realización que permite su aplicación.

El primer llamado que se hace para interpretar la norma fundamental es al legislador. En efecto, cada acto normativo que emana de su competencia supone la positivación de una determinada interpretación constitucional, según la materia de que se trate. Dicha interpretación se ve plasmada en la norma que finalmente es aprobada luego del proceso legislativo, donde participan la Cámara de Diputados, el Senado y el presidente de la República. Con cada iniciativa legislativa, con cada indicación, con cada votación, estas tres instituciones presentan su propia interpretación de la Constitución, en aquella dimensión que atañe al proyecto legislativo en cuestión. Una vez aprobada, esa norma concretiza una disposición o un principio constitucional, articulando la aplicación de la norma fundamental. Ciertamente, no todas las disposiciones legales realizan esta interpretación constitucional de la misma forma; existe una diferencia de grado en relación con la materia de la que se trate y el tipo de norma constitucional que puede verse identificada en la norma legal. Así, es posible que la interpretación constitucional que hace el legislador sea más evidente, por ejemplo, en la regulación de un sistema de educación pública de calidad, que en la aprobación de un montepío; pero se trata de diferencias de grado e intensidad. Algo parecido puede decirse respecto del ejercicio de la potestad reglamentaria del presidente de la República, particularmente la autónoma. En ejercicio de esta potestad, el presidente de la República realiza una interpretación de las normas que establecen su competencia normativa infralegal, de las materias reservadas a la ley y de las demás normas que establecen el marco jurídico de la acción de los poderes públicos, lo que es un requisito básico para el ejercicio de su potestad. 
Esta revista forma parte del acervo de la Biblioteca Jurídica Virtual del Instituto de Investigaciones Jurídicas de la UNAM

Ahora bien, cuando se produce algún conflicto en la interpretación constitucional propuesta por estos $\mathrm{u}$ otros actores institucionales, quienes son llamados a zanjar dicha controversia son los tribunales, especialmente el Tribunal Constitucional. En efecto, los conflictos que puedan suscitarse durante el proceso legislativo o en el ejercicio de la potestad reglamentaria, que versan sobre interpretaciones constitucionales contrapuestas o contradictorias y que son sostenidas por grupos políticos, generalmente antagónicos, serán resueltos por el Tribunal Constitucional. Así, la participación del tribunal y, en consecuencia, la determinación jurisdiccional de la interpretación constitucional es accidental, ya que depende de tres factores de hecho: que se presente una diferencia en la interpretación constitucional durante el proceso legislativo o el conocimiento de la norma reglamentaria, que dicha diferencia no pueda ser resuelta por la vía deliberativa y que la minoría parlamentaria decida recurrir al Tribunal Constitucional para (intentar) resolver dicha disputa (a su favor).

2. Asimismo, una serie de actores no institucionales también ejercen como intérpretes de la Constitución, en lo principal la doctrina constitucional y la ciudadanía en general, lo que Häberle ha denominado la sociedad abierta de los intérpretes de la Constitución. ${ }^{16}$ Esto se materializa en una serie de acciones y decisiones tomadas por actores que tienen diversos grados de relación con la Constitución, los que la realizan permanentemente en el ejercicio de sus actividades habituales.

Cuando un ciudadano se siente vulnerado en el legítimo ejercicio de un derecho fundamental, recurre a la corte de apelaciones a solicitar la tutela de dicho derecho, exigiendo el restablecimiento del orden jurídico. Al ejercer la acción constitucional, el ciudadano está proponiendo determinada interpretación constitucional, a partir de la cual el ejercicio de su derecho invocado encuentra protección ante una vulneración que, según su propuesta de interpretación constitucional, es contraria a la Constitución. Por el contrario, el recurrido contestará la acción proponiendo una interpretación de la Constitución alternativa, a partir de la cual el acto u omisión impugnado no es incompatible con la Constitución y, por tanto, no vulnera el legítimo ejercicio del derecho invocado por el actor. En dicha relación dialéctica, la Corte discurre argumentativamente entre ambas interpretaciones constitucionales propuestas por las partes y le otorga respaldo institucional a una de ellas; es

16 Häberle, Peter, "La Constitución como cultura", Anuario Iberoamericano de Justicia Constitucional, núm. 6, 2002; El Estado constitucional, México, Universidad Autónoma de México, 2003. 
Esta revista forma parte del acervo de la Biblioteca Jurídica Virtual del Instituto de Investigaciones Jurídicas de la UNAM

decir, la interpretación constitucional presente en la decisión judicial tiene como antecedente una que proviene de la ciudadanía, en forma inorgánica y carente de un respaldo institucional previo, pero que la Corte la respalda o valida con su sentencia.

Esto es relevante, ya que pone de manifiesto que la sociedad genera algún tipo de interpretación constitucional, la cual sirve de antecedente para aquella que se institucionaliza en los tribunales. Ante un eventual conflicto que pueda generarse en el seno de la sociedad, relativo a la interpretación constitucional de una norma o, lo que es más frecuente, relativo al ejercicio de los derechos, los tribunales entran en escena, resolviendo el conflicto a favor de alguna de las partes; sin embargo, dicha decisión no es tomada en abstracto, sino que parte de la base de la contradicción en la interpretación constitucional propuesta por las partes y se encuentra, por tanto, condicionada por aquella que llega precisamente desde la sociedad.

¿Qué es lo relevante de la presente constatación? Que la Constitución es interpretada permanentemente, todos los días, por una serie de operadores de distinta entidad, y que la regla general es que dichas interpretaciones tengan una validez en el contexto de sus respectivos ámbitos de acción, sin que ello genere, en la mayoría de los casos, conflictos de interpretación que deban ser resueltos jurisdiccionalmente.

Lo propio sucede con el proceso legislativo, ya que la gran mayoría de las interpretaciones constitucionales que se encuentran presentes en la discusión de los proyectos de ley no alcanzan a tener un nivel de conflictidad que los lleve a solicitar la determinación jurisdiccional de la interpretación de la Constitución. Sólo por excepción determinados conflictos llegan a ser resueltos por un tribunal, y sólo como consecuencia de una controversia entre partes, en la que una de éstas decide acudir al órgano jurisdiccional como forma de zanjar la disidencia constitucional.

De este modo, la gran mayoría de las veces en que se aplica e interpreta la Constitución, sea en un proceso legislativo o en el ejercicio cotidiano de los derechos, la interpretación resulta de un proceso más o menos dialéctico y horizontal, donde no participa ningún tribunal de justicia. Por el contrario, la interpretación constitucional que se realiza en sede jurisdiccional es accidental y esporádica, y tiene como insumo las interpretaciones constitucionales propuestas por las partes en conflicto.

Ello lleva a la configuración de un sistema de distribución de competencias en materia de interpretación constitucional, donde la interpretación más frecuente se encuentra presente en el legislador y en la propia práctica 
Esta revista forma parte del acervo de la Biblioteca Jurídica Virtual del Instituto de Investigaciones Jurídicas de la UNAM

constitucional de la ciudadanía, mientras que los tribunales tienen una competencia que ejercen de manera eventual y a partir de la interpretación que las partes en conflicto le proponen. En este contexto, el legislador cumple una función clave en esta materia, determinando el contenido material de importantes garantías constitucionales, ya sea por la vía de la reserva de ley como garantía en la regulación del ejercicio de los derechos fundamentales, o bien por la aplicación del propio principio de legalidad.

\section{LOS CRITERIOS DE INTERPRETACIÓN \\ DE LAS NORMAS CONSTITUCIONALES QUE CONTIENEN DERECHOS FUNDAMENTALES}

1. En este contexto, de apertura de la interpretación constitucional, nos encontramos frente a un proceso que carece de criterios o parámetros objetivos. A diferencia de la interpretación de la ley, que posee reglas más o menos objetivadas, la interpretación constitucional se presenta como una especie dentro del género de la interpretación jurídica, que comparte ciertas características con la interpretación legal, pero que cuenta con elementos diferenciadores. La presencia de estas particularidades en la interpretación constitucional la transforman en un ejercicio hermenéutico diferente, sujeto a exigencias propias y adicionales respecto de la interpretación legal.

Precisamente, los criterios de interpretación que confluyen en la escuela histórica de Savigny ${ }^{17} \mathrm{y}$, generalmente, contenidas en los códigos civiles, ${ }^{18}$ son uno de los testigos privilegiados del cambio de paradigma que ha experimentado el derecho en el último medio siglo. Hijos de un contexto histórico monopolizado por el Estado de derecho liberal-burgués del siglo XIX, en el que la ley era la máxima expresión del derecho, generada en un parlamento

17 Elementos gramatical, sistemático, histórico y teleológico. En todo caso, sálvese el cuestionamiento que de esta teoría se formula en Guzmán Brito, Alejandro, Las reglas del Código Civil de Chile sobre interpretación de las leyes, Santiago, Lexis Nexis, 2007, pp. 209-213; según el autor no existe prueba documental fidedigna que permita afirmar que Andrés Bello, redactor del Código Civil chileno, haya seguido los criterios de Savigny.

18 En el caso del Código Civil chileno, estas reglas se encuentran enunciadas en los artículos 19-24, que data de 1855. Para una revisión de la evolución histórica experimentada por este cuerpo legal, véanse los trabajos recogidos: Guzmán Brito, Alejandro, Las reglas del Código Civil de Chile sobre interpretación de las leyes, Santiago, Lexis Nexis, 2007 y Guzmán Brito, Alejandro, El Código Civil de Chile (1855-2005), Santiago, Lexis Nexis, 2007. 
Esta revista forma parte del acervo de la Biblioteca Jurídica Virtual del Instituto de Investigaciones Jurídicas de la UNAM

socialmente homogéneo, donde los conflictos jurídicos no llegaban a tener relevancia constitucional, estos criterios pretendían un nivel de certeza en la interpretación de las normas que parece incompatible con la positivación constitucional de contenidos materiales abiertos e indeterminados. Esta pretensión se justificaba a partir de la desconfianza reinante en la arbitrariedad del juez, que intenta limitarse al vincular su labor a la ley, restándole espacio para decidir. En consecuencia, se postula la existencia de una interpretación correcta de la ley, aquella que tuvo en consideración el legislador al momento de redactar la norma. ${ }^{19}$

El propio enunciado gramatical de estos elementos de interpretación da cuenta de un ejercicio que busca extraer de las entrañas de la norma su verdadero sentido o significado, ignorando tanto la posibilidad de conflicto entre diversas interpretaciones como de evolución en el contenido material de las normas. El recurso al tenor literal, al contexto histórico de generación de la norma, a su espíritu, al espíritu general de la legislación, en fin, a la equidad natural, los cuales dan cuenta de un sistema que busca encontrar aquella única interpretación posible de la norma, sin considerar que el derecho es un fenómeno esencialmente cultural, resultado de las particulares combinaciones de las fuerzas políticas de un determinado momento histórico.

En suma, estas reglas no buscan la construcción de un significado en un proceso democrático y participativo, sino su alumbramiento. Es razonable que así sea, ya que pertenecen a una realidad histórica muy distinta a la presente. Sin embargo, estos criterios quedan claramente en entredicho en la interpretación constitucional contemporánea, atendido el contenido normativo de la Constitución y la vigencia normativa del principio democrático en su construcción e interpretación.

No obstante, es útil recordar que estos criterios clásicos de interpretación legislativa han sido revisados y morigerados en algunos ordenamientos extranjeros, tratando de adaptar las normas a los contextos sociales en que se aplican. Así, en el caso del Código Civil español (artículo 3.1): "El contexto, los antecedentes históricos y legislativos, y la realidad social del tiempo en que han de ser aplicadas, atendiendo fundamentalmente al espíritu y finali-

19 Esta tendencia estuvo especialmente presente en los primeros intérpretes del Código Civil chileno que, al entender que el Código acogía un sistema literalista, redujeron el ejercicio de interpretación sólo a las situaciones de oscuridad de la ley. Quintana Bravo, Fernando, Interpretación y argumentación jurídica, Santiago, Editorial Jurídica de Chile, 2006, pp. 217-220. 
Esta revista forma parte del acervo de la Biblioteca Jurídica Virtual del Instituto de Investigaciones Jurídicas de la UNAM

dad de aquellas", se incorporan a los criterios clásicos de interpretación de las normas legales, tratando de superar la concepción tradicional existente en esta materia. En palabras de Diez-Picazo, se trata que: "La aplicación de la ley no vaya contra la realidad social en el tiempo en que se efectúa, que puede ser distinta de la que existía cuando se promulgó"; ${ }^{20}$ en efecto, la realidad que va cambiando está relacionada con paradigmas de diversa naturaleza, que son "factores políticos, sociales, económicos, culturales, estados de conciencia u opinión pública, y convicciones y creencias imperantes en un momento dado en determinada sociedad". ${ }^{21}$

En todo caso, lo anterior no supone una modificación de las normas legales, sino que es una actualización hasta donde lo permita el contenido del texto, advirtiendo que su utilización reclama prudencia porque está latente el peligro de la arbitrariedad al entregar al criterio subjetivo del juez, apreciaciones tan delicadas como la conciencia moral de un pueblo. ${ }^{22}$

2. Sin perjuicio de esta excepcional apertura hermenéutica, propuesta en ciertos ordenamientos legales, es evidente que las actuales notas distintivas de la Constitución contemporánea son incompatibles con una metodología que descanse en las clásicas normas de interpretación. La presencia de normas de principio, cuyo contenido material indeterminado es el reflejo de la pluralidad de la comunidad política, abre la puerta a la necesidad de construir un significado del enunciado normativo, complementando estos criterios -más propios de la interpretación de normas con estructura de regla, siguiendo la clasificación de Alexy - con aquellos que incorporan la compleja estructura de las normas constitucionales, condicionados por la positivación de principios materiales.

En este contexto se ha afirmado que las normas con estructura de principio establecen más que una conducta debida a partir de la verificación del supuesto de hecho, verdaderos mandatos de optimización, ${ }^{23}$ sin que sea posible deducir entonces de cada enunciado formal un único y correcto contenido normativo. Es en este tipo de normas donde se hace patente la tensión que existe entre la pretensión de permanencia de toda norma fundamental y el carácter evolutivo de los destinatarios de la misma, lo que

20 Diez-Picazo, L. y Gullón, A., Sistema de derecho civil, 11a. ed., Madrid, Tecnos, 2000, pp. 369-378.

21 Ibidem, p. 170.

22 Ibidem, pp. 170 y 171.

23 Comparando a Alexy, Robert, Teoría de los derechos fundamentales, Madrid, Centro de Estudios Constitucionales, 2002. 
Esta revista forma parte del acervo de la Biblioteca Jurídica Virtual del Instituto de Investigaciones Jurídicas de la UNAM

obliga a considerar el contexto histórico (social, político y cultural) en el que ha de aplicarse la Constitución.

En consecuencia, salvo la minoritaria situación de las disposiciones constitucionales claras y con un enunciado normativo preciso y directo, la labor interpretativa en el ámbito constitucional implica una verdadera operación de creación de derecho, considerando la norma y las especificidades del caso concreto, pero en la que la decisión tendrá un gran componente político. ${ }^{24}$

Por ello, los clásicos criterios de interpretación (de la ley) son complementados por otros que atienden a las particularidades propias de la norma interpretada; avisar sobre la especificidad de la interpretación constitucional no significa denunciar los criterios tradicionales como inútiles. Por el contrario, el recurso a nuevos criterios implica reconocer tanto las bondades de los primeros como una primera herramienta de aproximación al texto de la norma, mas asumiendo las limitaciones que tienen frente a una Constitución que desborda las pretensiones de objetivación del ordenamiento jurídico decimonónico.

Sin embargo, la Constitución contemporánea asume como dato primario, como ya lo vimos, la pluralidad de la democracia, por lo que el carácter abierto e indeterminado de sus enunciados, tan lejano a los valores absolutos de antaño, puede generar un necesario espacio de ambigüedad en el proceso de decisiones constitucionales, propia del pluralismo político.

Ahora bien, esta apertura e indeterminación en el contenido de las normas constitucionales de principio, entre ellas las de derechos fundamentales, podría generar un espacio de discrecionalidad en la interpretación constitucional, a lo que se suma la ausencia de criterios objetivos para la realización de ésta. ${ }^{25}$ Ello se ve incrementado por la multiplicidad de fundamentaciones teóricas a partir de las cuales se puede leer la Constitución (de carácter político, ideológico, incluso religioso), lo que puede derivar en una merma de la igualdad ante la ley y de la predictibilidad de las decisiones judiciales, en la medida que sus decisiones no se hagan cargo satisfactoriamente de este espacio de discrecionalidad que se abre con la combinación de la apertura de las normas y la ausencia de criterios objetivos para su interpretación.

24 Kelsen, Hans, Teoría pura del derecho, México, Porrúa, 2002, pp. 351 y ss.

25 Aldunate Lizana, Eduardo, “Aproximación conceptual y crítica al neoconstitucionalismo”, Revista de Derecho, vol. 23, núm. 1, 2010, pp. 79-102. 
Esta revista forma parte del acervo de la Biblioteca Jurídica Virtual del Instituto de Investigaciones Jurídicas de la UNAM

Ante ello, se ha señalado que la jurisprudencia constitucional se encuentra sometida a una mayor exigencia argumentativa. ${ }^{26}$ Como tras la Constitución no hay respuestas correctas o incorrectas, sino unas sostenidas por argumentos mejores o peores, la exigencia adicional de argumentación se sustenta, precisamente, en la necesidad de evitar que la decisión jurisdiccional que institucionaliza la interpretación de la Constitución se sustente en argumentos subjetivos y parciales (políticos o religiosos), en una discrecionalidad que roza la arbitrariedad. Así, se entienden los esfuerzos de un sector de la doctrina y la jurisprudencia por mostrar la ponderación como un ejercicio objetivo de interpretación de las normas constitucionales (aplicando los tres subprincipios clásicos que integran la proporcionalidad), pero ello evidentemente no tiene la objetividad ni rigurosidad que la formulación pretende lograr.

De este modo, la argumentación que justifica la interpretación constitucional propuesta jurisdiccionalmente debe sustentarse en argumentos que sean susceptibles de ser compartidos intersubjetivamente y que no obedezcan a la mera subjetividad del intérprete, como sucede con el recurso a versiones particulares de la verdad sobre la base de concepciones religiosas, filosóficas o morales, la cita constante a las Actas de la Comisión de Estudios de la Nueva Constitución o la referencia a las encíclicas papales, elementos tan comunes y peculiares de la jurisprudencia chilena. Dicha subjetividad de un argumento particular, que no es susceptible de ser compartido ni respetado intersubjetivamente, se convierte en un argumento de autoridad que intenta cerrar la deliberación. Su incompatibilidad con el Estado democrático de derecho termina finalmente por deslegitimarlo.

\section{LA INTERPRETACIÓN Y ATRIBUCIÓN DE CONTENIDO}

DE LAS NORMAS DE DERECHOS FUNDAMENTALES:

EL CASO DE LA LIBERTAD DE EMPRESA

1. Los presupuestos teóricos antes expuestos tienen directa incidencia, como se verá, en la forma en que se distribuyen las competencias para la interpretación de los derechos fundamentales. No se trata de competencias atribuidas formalmente por el ordenamiento jurídico, sino de la forma en que los distintos actores de la práctica constitucional interpretan la Carta.

26 En comparación con Atria, Fernando, "El Tribunal Constitucional y la objeción democrática", Revista Chilena de Derecho, vol. 20, 1998, pp. 367-378. 
Esta revista forma parte del acervo de la Biblioteca Jurídica Virtual del Instituto de Investigaciones Jurídicas de la UNAM

Todos los actores participan de la interpretación constitucional en un ejercicio que tiene gran relevancia para la configuración del sistema normativo que regula a la sociedad, pero que carece de una rigurosidad proporcionada a su importancia. Dicha falta de rigurosidad deriva, en parte, de la propia estructura de la norma interpretada, cuya amplitud y ambigüedad da cabida a diversas interpretaciones; mas también se debe al escaso desarrollo de la función que cumplen los intérpretes no institucionales de la Constitución.

2. A este respecto, y sólo con el fin de evidenciar el papel determinante que cumple la interpretación constitucional en la configuración del ordenamiento jurídico, es posible ejemplificar este análisis con una de las instituciones más representativas del diseño institucional chileno construido desde 1980: la libertad de empresa, la cual como se sabe, está establecida en el artículo 19 Núm. 21 de la Constitución, que señala que se asegura a todas las personas el derecho a desarrollar cualquier actividad económica, con las limitaciones que impone la ley, la moral, el orden público y la seguridad nacional. Además, en su inciso 2 se establecen las condiciones conforme a las cuales el Estado podrá desarrollar estas mismas actividades, sujetando su ejercicio a una ley de quórum calificado que lo autorice.

De la norma antes citada es posible concluir que sólo el inciso 1 formula o protege un derecho fundamental: el derecho a la libertad económica, mientras que el inciso 2 sólo contempla las reglas formales a través de las cuales se regulará la actividad empresarial del Estado; es decir, la Constitución contempla una norma para el derecho fundamental y otra para el estatuto del Estado empresario. Ahora bien, ¿qué establece realmente el inciso 2 del artículo 19 Núm. 21 de la Constitución? Se ha argumentado que a partir de dicha norma se estructura el orden público económico que rige en nuestro país y se da vida y aplicación al principio de subsidiariedad en materia económica, condicionando seriamente la intervención estatal en la actividad económica empresarial. ${ }^{27}$

Sin entrar en detalle de dicha institución, objeto que escapa a las pretensiones del presente trabajo, nos interesa poner acento en un aspecto: el contenido que se le atribuye al orden público económico en general, y al estatuto del Estado empresario en particular, no se desprende, como se verá, pura y simplemente del texto de la Constitución; es decir, el contenido material de este concepto no es autoevidente. Por el contrario, ha sido construido hermenéuticamente por la jurisprudencia y, especialmente, por la doctrina. Ha sido la doctrina la

27 Fermandois V., Arturo, Derecho constitucional económico, Santiago, Ediciones Universidad Católica de Chile, t. I, 2000. 
Esta revista forma parte del acervo de la Biblioteca Jurídica Virtual del Instituto de Investigaciones Jurídicas de la UNAM

que a partir de la interpretación del texto vigente ha afirmado que la Constitución consagra determinada institución o protege determinado modelo.

Lo anterior queda en evidencia si se analizan los dos pilares fundamentales en el que descansa la doctrina antes expuesta. Así, por un lado, una interpretación originalista de la Constitución, que a través de una lectura parcial, acrítica y sin mayor discernimiento sobre las opiniones de los comisionados que puedan poseer mayor o menor "voluntad constituyente", ha buscado perpetuar determinado diseño institucional, cerrando el debate característico del proceso democrático en torno a las instituciones de dicho diseño. Por tanto, se ha hecho explícita la concepción de la Constitución que se esconde tras esta teoría de la interpretación constitucional: una carta testamento, cerrada e inmodificable, que se protege mediante el argumento de autoridad de una interpretación originalista.

Sin embargo, como sucede con todo órgano legislativo colegiado, aunque el fruto de su trabajo es una unidad normativa determinada esconde la pluralidad que se genera durante el proceso legislativo, en el cual se expresan una serie de opiniones destinadas a influir sobre el texto que será aprobado en definitiva. Como es de esperar, las opiniones vertidas durante el proceso nomogenético presentan diversos grados de disenso, ante la evidente falta de unanimidad frente a los proyectos que se discuten. En definitiva, la voluntad de estos cuerpos no es equivalente a la voluntad unitaria de una sola persona.

En consecuencia, no todas las opiniones expresadas en el seno de estos cuerpos colegiados se identifican con el resultado final; de hecho, muchas de dichas opiniones son opuestas, y hasta contradictorias, con el texto finalmente promulgado. Waldron lo expresa con claridad: "No todo lo que se dice en el debate legislativo puede poseer autoridad legislativa". ${ }^{28}$ Por esta razón no todas las opiniones que constan en las actas de estos cuerpos legisladores son fuente de legitimación o de esclarecimiento para explicar el sentido y alcance de las normas finalmente aprobadas. Así, antes de citar un documento con la apariencia de ser la historia fidedigna del establecimiento de la norma, es necesario realizar un ejercicio de discernimiento e identificar qué opiniones sirven, efectivamente, para justificar, interpretar o explicar las normas actualmente vigentes. En otras palabras, es necesario distinguir dos momentos en el proceso nomogenético: por un lado, el proceso de deliberación, y, por el otro, la aprobación de la norma. Sólo mediante un proceso de discernimiento, un intérprete podría recurrir

28 Waldron, Jeremy, Derecho y desacuerdos, Madrid, Marcial Pons, 2005, p. 53. 
Esta revista forma parte del acervo de la Biblioteca Jurídica Virtual del Instituto de Investigaciones Jurídicas de la UNAM

a la interpretación originalista, rigor que en Chile no se satisface por los cultores de esta práctica.

Por otro lado, la interpretación constitucional que puede realizar la doctrina se sustenta, por cierto, en preceptos constitucionales a los que se recurre para dotar de contenido material a ciertas normas y construir estas instituciones, pero no a todas las normas ni a cualquiera, sino a ciertos enunciados normativos seleccionadas. Por ejemplo: el contenido material del estatuto del Estado empresario se ha construido a partir de una interpretación selectiva de la Constitución, donde se ha privilegiado cierta lectura del principio de subsidiariedad en desmedro de otras normas constitucionales, por ejemplo, la igualdad de oportunidades (artículo 1o., inciso 5) o el principio de solidaridad (artículo 3o.) o las limitaciones que el mismo artículo 19 Núm. 21 establece para el ejercicio de dicha actividad.

Ciertamente, todas estas normas tienen legitimidad suficiente para contribuir en el ejercicio hermenéutico que supone dotar de contenido material a las normas abiertas e indeterminadas, sin embargo, hace evidente que se trata de un contenido que se construye a partir de una serie de decisiones (políticas, metodológicas, hermenéuticas), no obstante, que ello no es autoevidente ni se desprende de la Constitución en términos necesarios. Se trata, en definitiva, sólo de una interpretación posible de la Carta, de entre varias posibles. $^{29}$

Aún más, el estatuto del Estado empresario que contempla la Constitución se reduce a dos requisitos formales: una autorización por ley de quórum calificado y el sometimiento de la actividad empresarial del Estado a la legislación común aplicable a los particulares. Nada más. Se trata de un contenido estrictamente formal, que se agota y verifica a partir de la actividad normativa del legislador (en ambos supuestos), sin límites de contenido material que específicamente haya contemplado la Constitución para dicha regulación. Los límites a través de los cuales se construye el referido estatuto son identificados y concretizados a partir de la hermenéutica, preferentemente, de una doctrina que ha permeado en la jurisprudencia.

Así, recurrir argumentativamente a la protección del derecho de propiedad, a la subsidiariedad del Estado, en fin, a la libertad económica, supone

29 Sobre la neutralidad, véase Bassa Mercado, Jaime, "Neutralidad política y enseñanza del derecho constitucional en Chile", en Henríquez, Miriam, Perspectiva del derecho constitucional desde el mirador del bicentenario, Santiago, Asociación Chilena de Derecho Constitucional, 2011, pp. 271-289. 
Esta revista forma parte del acervo de la Biblioteca Jurídica Virtual del Instituto de Investigaciones Jurídicas de la UNAM

una determinada concepción del rol del Estado en la sociedad, pero ello no se desprende en términos necesarios de la Constitución. No se trata del resultado de una investigación científica y neutra que dogmatiza en torno al derecho vigente, sino de una construcción discursiva, legítima, pero que, en tanto resulta de un acto de voluntad, arroja resultados eventuales, relativos y cuestionables. Incluso una interpretación sistemática y armónica de todo el texto nos llevaría a una relativización de los diversos valores que este texto protege, en particular los que se han incorporado en su proceso de democratización desde la reforma constitucional de 1989 (proceso de reforma y democratización que ya sobrepasa la treintena de leyes de reforma constitucional). Ello depende, en definitiva, de las opciones particulares del intérprete, antes que de las opciones del constituyente.

No debemos olvidar que la Constitución contemporánea está llamada a garantizar la apertura del proceso democrático, no a cerrarlo a través de argumentos de autoridad. Es en esa tradición del constitucionalismo occidental (tributaria del constitucionalismo liberal, del social y del democrático), donde debería insertarse la Constitución chilena vigente.

3. Ahora bien, si la actual conformación del Estado empresario obedece más a la construcción interpretativa que cierto sector de la doctrina realiza del artículo 19 Núm. 21 de la Constitución, más que su contenido normativo, es posible cuestionar la función que ha tenido hasta ahora la interpretación constitucional en la configuración del ordenamiento jurídico chileno.

En efecto, la doctrina y la jurisprudencia han cumplido, en este caso, una función clave en la determinación del contenido material del estatuto del Estado empresario. La interpretación combinada de determinadas normas constitucionales ha llevado a configurar un estatuto jurídico basado en la subsidiariedad, la propiedad privada y la libertad económica, principios presentes desde luego en el texto constitucional. Sin embargo, se han excluidos otros principios también presentes en la Constitución, como el de solidaridad o la igualdad de oportunidades, los que llevarían a una forma distinta de entender estas normas, rediseñando el modelo constitucional que ha imperado hasta ahora.

En otras palabras, la construcción tradicional del derecho a la libertad de empresa y el rol secundario del Estado en la actividad empresarial es un contenido posible constitucionalmente, mas no necesario; es decir, una selección y combinación diferente de los principios constitucionales podría arrojar, legítimamente, una configuración diferente en esta materia, sin que se modifique o vulnere el mismo texto constitucional. 
Esta revista forma parte del acervo de la Biblioteca Jurídica Virtual del Instituto de Investigaciones Jurídicas de la UNAM

4. El que la Constitución no posea un contenido fijo para las normas constitucionales de principio, como lo acabamos de ver, configura precisamente la garantía de libertad política de los ciudadanos, lo que se identifica en la indeterminación de estas normas: su concreción posterior por el legislador supone proteger la autodeterminación normativa del pueblo soberano en aquellas materias que no pueden quedar predeterminadas por la Constitución. En ese contexto se entiende, por ejemplo, la reserva de ley como garantía al ejercicio de los derechos fundamentales (19 Núm. 26) o el propio principio de legalidad como contenido de ciertas garantías (19 Núm. 3) de la Carta.

El fin de esta apertura que presenta la Constitución en determinadas normas, ya sea por la indeterminación de su contenido que deriva de su estructura normativa o por la imposibilidad de regular en detalle ciertas materias, es garantizar que su concreción posterior será realizada según la valoración del momento histórico de su aplicación, y no en el vigente al momento de su promulgación. Así, las normas constitucionales podrán ser realizadas y concretadas (en definitiva, interpretadas) por los diversos actores del proceso constitucional, comenzando por el legislador, representante de la pluralidad política y único competente para regular el ejercicio de los derechos fundamentales y, en algunos casos, hasta su contenido.

Ahora bien, dada la relación jerárquica que existe entre la Constitución y la ley, pero considerando la indeterminación de ciertas normas y materias en el modelo contemporáneo de la Constitución, es necesario preguntarse ¿cuánta libertad tiene el legislador para concretar el contenido de estas normas constitucionales? En efecto, al momento de configurar el ordenamiento jurídico, el legislador reconoce límites formales y materiales en la Constitución. Los primeros son evidentes y se relacionan, principalmente, con un sistema de distribución de competencias entre los órganos del Estado y con determinados procedimientos para su funcionamiento; sin embargo, los segundos son más difusos, por cuanto a la relación con aquellos enunciados constitucionales de contenido abierto e indeterminado.

Así, por ejemplo, en la regulación legal de un eventual matrimonio entre personas del mismo sexo, podríamos identificar un límite material en el artículo 1o., inciso 2, de la Carta; pero habría que convenir que el concepto de familia es abierto, no unívoco, por lo que el recurso al límite material deja de tener la claridad que se pretende. De hecho, el concepto constitucional de familia es polisémico a tal punto que es congruente con la existencia de un régimen 
Esta revista forma parte del acervo de la Biblioteca Jurídica Virtual del Instituto de Investigaciones Jurídicas de la UNAM

de filiación que distinga entre hijos legítimos, ilegítimos y naturales, o no. Es congruente con la existencia de divorcio vincular, o no. Es congruente con un sistema público de educación sexual, o no. Su concretización depende, como se ve, de la configuración del ordenamiento infraconstitucional, lo que evidencia el carácter eventual del contenido de este tipo de normas constitucionales. El punto está en que en determinado momento de la historia, la sociedad dejó de creer que el sistema diferenciado de filiación era compatible con el concepto de familia y lo modificó a través de sus legisladores. De esta manera, no es posible afirmar que el contenido constitucional del concepto de familia se encuentre cerrado o predeterminado, por el contrario, es un concepto abierto, polisémico, que permite diversas concreciones.

Dicha concreción, como se ha señalado, es realizada por los diversos actores constitucionales, principalmente por el legislador, el juez y la doctrina, a través de la interpretación constitucional. Dado que los parámetros de interpretación de la Constitución no son objetivos, se genera un espacio importante para la discrecionalidad del intérprete. Ello deriva en la mayor o menor valoración que éste puede hacer de los principios, criterios y elementos disponibles para la interpretación constitucional.

Dada la indeterminación de las normas constitucionales de principio y la falta de criterios objetivos para la interpretación constitucional, pareciera que sólo la deliberación democrática en sede legislativa puede evitar la subjetividad del intérprete-juez y del intérprete-doctrina. Estos últimos se encuentran sometidos a sus propios condicionamientos culturales, que pueden influir indebidamente en su labor. En el caso de la doctrina, este riesgo puede tender a diluirse, dado que forma parte de un proceso de discusión académica entre pares, cuya influencia en el derecho positivo es indirecta; sin embargo, la labor del intérprete-juez, en particular del Tribunal Constitucional, sí puede constituir un mayor riesgo de subjetividad en la interpretación, dada la debilidad de sistema de responsabilidad de los ministros y la casi nula deliberación pública en el sistema de nombramiento.

Este riesgo a la subjetividad del intérprete es aún mayor cuando se trata de normas constitucionales de contenido abierto que se refieren a materias sensibles desde el punto de vista ideológico, moral o religioso. Así, aquella neutralidad que se predica respecto del Estado pareciera estar mejor garantizada en el proceso deliberativo de un órgano de representación popular, que en organismos jurisdiccionales no siempre colegiados. 
Esta revista forma parte del acervo de la Biblioteca Jurídica Virtual del Instituto de Investigaciones Jurídicas de la UNAM

\section{CONCLUSIONES}

1. La apertura de los enunciados constitucionales con estructura de principio, como lo son los de derechos fundamentales, constituye una garantía de libertad política, ya que su concreción posterior permite que la propia comunidad determine el contenido de sus normas fundamentales. No corresponde a la Constitución cerrar el contenido del pacto político que se plasma en ella, sino garantizar la apertura del proceso democrático para su revisión y realización permanente, manteniendo un techo ideológico abierto.

2. En este ejercicio de concretización, varios actores se encuentran llamados a interpretar la Constitución, siendo el primero de ellos el Legislativo, como órgano colegiado y representante tanto de las mayorías como de las minorías presentes en la sociedad.

3. Junto al Legislativo también los tribunales interpretan la Constitución, pero principalmente ante los conflictos que puedan presentarse entre actores que enfrentan diversas interpretaciones. Entre estos conflictos destacan las diferencias que se presentan entre parlamentarios durante la tramitación legislativa o entre particulares en el ejercicio de sus derechos fundamentales. En ambos escenarios, las partes en conflicto presentan sus interpretaciones constitucionales a un tribunal, que resuelve inclinándose por una de ellas.

4. En este escenario, donde el contenido de las normas de derechos fundamentales es indeterminado y cuya concretización se realiza a través de la interpretación constitucional, las características de organización del Congreso Nacional lo erigen como el actor más idóneo para la interpretación de los derechos fundamentales. En efecto, tanto su funcionamiento colegiado como su representación democrática le entrega sentido tanto a la reserva de ley como al principio de legalidad, instrumentos normativos mediante los cuales se garantiza la posición de privilegio del Legislativo en la regulación del ejercicio de los derechos, sin embargo, también en la determinación de su contenido, de carácter eventual y no necesario.

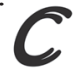

Fecha de recepción: 14 de noviembre de 2016.

Fecha de dictamen: 6 de marzo de 2017. 